Research Article

\title{
Comparative Evaluation of Different Hand Sanitizers
}

\author{
Ashwini Ramchandra Ingole*, Viral Uttam Ramani, Manish Anant Kamble, Disha Motiram Dhabarde, Jagdish Radheshyam Baheti \\ Kamla Nehru College of Pharmacy, Butibori, Nagpur-441108 (M.S.) India. \\ *Corresponding author's E-mail: jbaheti@gmail.com
}

Received: 18-03-2021; Revised: 21-05-2021; Accepted: 28-05-2021; Published on: 15-06-2021. \begin{abstract}
Hygiene is associated with prevention of disease and promoting health. The importance of hygiene is universally recognized, and evidence based. Hands are the part of body which helps in touching various objects and surfaces and performing various works. They are involved in cooking and eating. Children and even adults are required to sanitize hands to prevent the contamination and entry of microbes in the body through hands. Bacteria associated with the hands are termed micro flora of the hands which include Propionibacterium, Staphylococcus and others which could be reduced depending on personal hygiene and environment of humans. Hand sanitizers are available in market and helps to clean and sanitize hands. The present work deals with the comparison of some brands of hand sanitizers for their antimicrobial activity. The activity is evaluated by using cup and plate method with Ciprofloxacin as a standard. Samples of four brands of sanitizers like Sterillium, IMC herbal, Savlon and Jungle Magic were prepared by diluting them. All the samples were poured in agar wells and the zone of inhibition of each sample was measured. From the study it was concluded that IMC herbal sanitizer was found to be more efficient than other sanitizers.
\end{abstract}

Keywords: Hygiene, Sanitizer, Ciprofloxacin, Zone of inhibition.

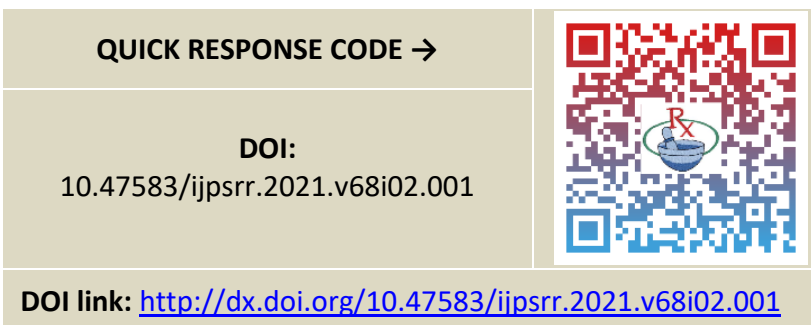

\section{INTRODUCTION}

T he word hygiene derived from Hygeia, the goddess of healing. ${ }^{1}$ Today, hygiene is associated with prevention of disease and promoting health. The importance of hygiene is universally recognized, and evidence based. ${ }^{2}$ Physical contact between people and between people and objects is a key vehicle for the transmission of pathogens. Therefore, effective hand hygiene is a very important in disease prevention. ${ }^{3}$

It is an integral procedure in the healthcare environment, with healthcare workers receiving regular training about hand hygiene procedures. ${ }^{4}$ In the community, outside of the healthcare environment, studies have reported an association between improvements in hand hygiene and reductions in rates of infectious diseases. ${ }^{3}$ It is estimated that simple hand washing could save one million lives a year and many public health campaigns worldwide have addressed "hand hygiene" with varying success. 5,6

Bacteria are prokaryotic heterogeneous group of unicellular organisms that possess a rigid cell that determines their shape as coccoid (spherical), bacillary (rod shaped), helical or common shaped. They are found almost everywhere in the environment such as air, stool, water, sewage, human body, wounds, and other solid surfaces. Some are beneficial in the body and others may cause problems.

Normal flora such as the Staphylococcus epidermidis produces antibiotics on the skin for protection against infection meanwhile the transient one acquired from the environment can be pathogenic. ${ }^{7}$ There are two types of normal flora on the skin, transient flora which are contacted from the external environment and the resident flora which is permanently found on the skin. ${ }^{8}$

Bacteria associated with the hands are termed micro flora of the hands which include Propionibacterium, Staphylococcus and others which could be reduced depending on personal hygiene and environment of humans. ${ }^{9}$ In $1847 \mathrm{Dr}$. Semmelweis Ignaz established a link between infection and unclean hands and demonstrated that washing could reduce transmission of puerperal fever (childbirth fever) a dreaded disease which had high mortality previously. ${ }^{10}$

The hands are part of body that are used for many dayto-day activities. It is extremely easy to meet different microbes and transfer them to other objects like doorknobs, pen, pencils, seats and even people. Surprisingly fingernails harbor the most bacteria found on the human hands. Children can contaminate their own food by playing in dust, easting with dirty hands and many unhygienic activities. The hands of a person may get contaminated with Staphylococcus aureus either by contact with genital areas, nose, toilet doors, playing with sand etc. Also, long nails of pupils tend to harbor more microorganisms than short nails. ${ }^{11,12}$ 
Hand sanitizers are preparations (liquid, gel, or foam) containing alcohol or non-alcohol based active ingredients which are applied to the hands in order to reduce the number of viable microorganisms on them. However, the CDC only recommends the use of alcoholbased hand sanitizers. ${ }^{15}$ Hand sanitizers are preferred over conventional hand washing with soap and water in terms of compliance because they are more effective in antimicrobial action, they are more convenient, and they are gentler on the skin and require less time for hand washing. ${ }^{14-16}$

\section{Study of anti-bacterial activity}

The disk diffusion test or Cup plate method is a test of the antibiotic sensitivity of bacteria. It uses antibiotic discs or solution to test the extent to which bacteria are affected by those antibiotics. In this test, antibiotics solution is poured in wells bored on an agar plate where bacteria have been inoculated, and the plate is left to incubate. If an antibiotic inhibits the growth of bacteria or kill them, zone of inhibition is created.

A pure bacterial culture is suspended in buffer, standardized to turbidity and swabbed uniformly across a culture plate. The antibiotic solution is poured in well on agar plate. The compound diffuses from the well into the agar. The concentration of the compound will be highest next to the disk, and will decrease as distance from the disk increases. If the compound is effective against bacteria at a certain concentration, no colonies will grow where the concentration in the agar is greater than or equal to the effective concentration. This is the zone of inhibition. These along with the rate of antibiotic diffusion are used to estimate the bacteria's susceptibility to that particular antibiotic. ${ }^{13}$

\section{MATERIALS AND METHODS}

Nutrient agar was procured from Hi media, Ciprofloxacin was obtained as gift sample from Zim Laboratories Ltd. Kalmeshwar. Different samples of sanitizers like Sterilium of Raman and Well Pvt. Ltd., Jungle Magic of M/s Cheryl Laboratories, IMC Herbal of International Marketing Corporation Pvt. Ltd., Savlon of Alliance Formulations were procured.

\section{Collection of Test Organisms}

The test organism used in present investigation was collected from college laboratory. The samples used were sub cultured and stored. 24 hours old Nutrient broth cultures of test bacteria was used.

\section{Collection Test Samples}

The samples of hand sanitizers were collected from different local stores.

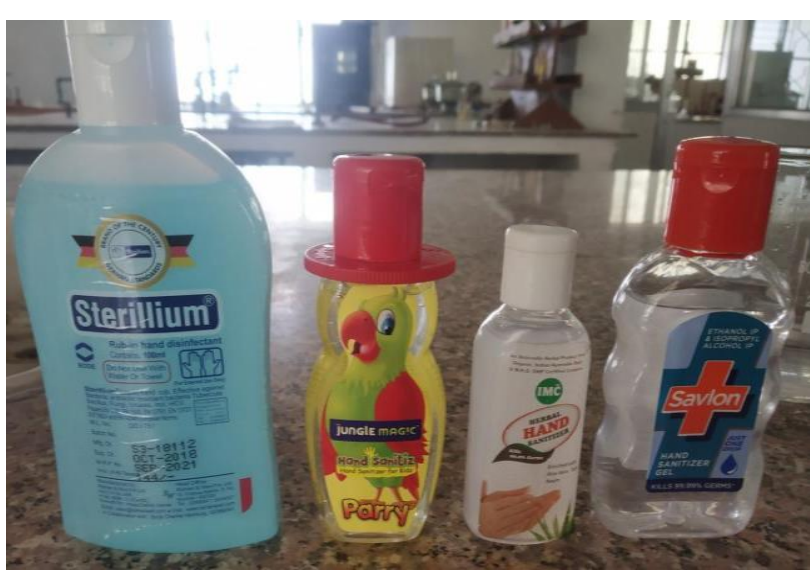

Figure 1: Sample of hand sanitizers

\section{Preparation of Solution}

Standard: Ciprofloxacin was dissolved in water and diluted to get a standard solution of $10 \mathrm{ug} / \mathrm{ml}$. The dilution was used in one well for comparison of other samples efficiency.

Test Samples: Samples of different hand sanitizers were diluted 10 time before use.

\section{Agar Diffusion Test to Determine Susceptibility of Test Organisms to Hand Sanitizers.}

\section{Test procedure:}

Cup plate methods was used for the evaluation of antimicrobial efficacy of hand sanitizers. ${ }^{17,18}$ Sterile Nutrient agar plates were inoculated with standardized test organisms. A sterile cotton swab was dipped into a test tube containing the inoculum and was rotated properly to allow maximum contact. The swab was then streaked over the surface of the medium three times while rotating the plate at $60^{\circ}$ angle after each application. The swab was also passed around the edge of the agar surface. The plate was kept stable for some time at room temperature. With the aid of a sterile $6 \mathrm{~mm}$ cork borer, 4 equally spaced holes were bored in the agar plate with a fifth hole in the center of the plate. 100 microliters of the hand sanitizer were then introduced into each of the 4 wells. This was done for test organisms and hand sanitizers. The plates were incubated for $24 \mathrm{~h}$ at $37^{\circ} \mathrm{C}$ in an upright position. They were then examined for zones of inhibition which indicated the degree of susceptibility or resistance of the test organism to the antibacterial agent. Inhibition zones were measured.

\section{RESULTS AND DISCUSSION}

\section{Anti-microbial activity of hand sanitizers}

The antimicrobial activity of different hand sanitizers was carried out by agar well diffusion method. The antimicrobial activity of hand sanitizers was studied against $\mathrm{S}$. aureus and compared with standard solution of Ciprofloxacin. 
Table 1: Anti-microbial activity of Sterillium, IMC, Savlon dilutions

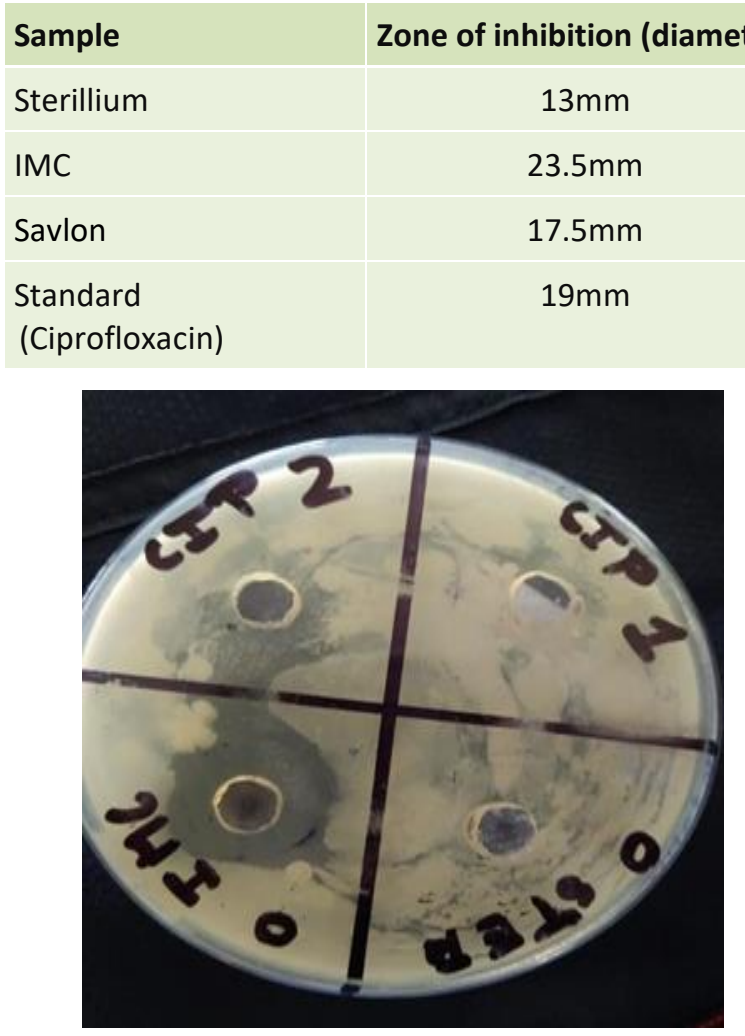

Figure 2: (Plate 1) Antimicrobial study of different hand sanitizers.

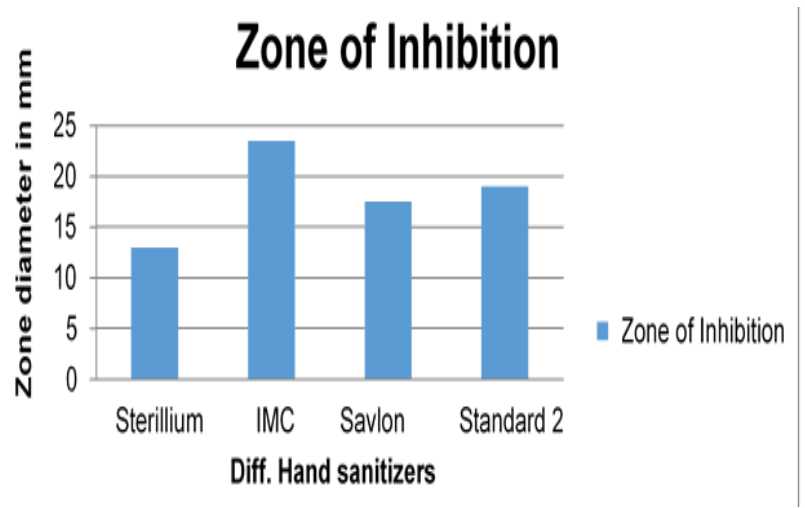

Figure 3: Antimicrobial study of different hand sanitizers.

Table 2: Anti-microbial activity of Sterillium, Jungle magic and IMC dilutions.

\begin{tabular}{|l|c|}
\hline Sample & Zone of inhibition (diameter) \\
\hline Sterillium & $12 \mathrm{~mm}$ \\
\hline Jungle magic & $18.5 \mathrm{~mm}$ \\
\hline IMC & $21 \mathrm{~mm}$ \\
\hline Standard (Ciprofloxacin) & $19 \mathrm{~mm}$ \\
\hline
\end{tabular}

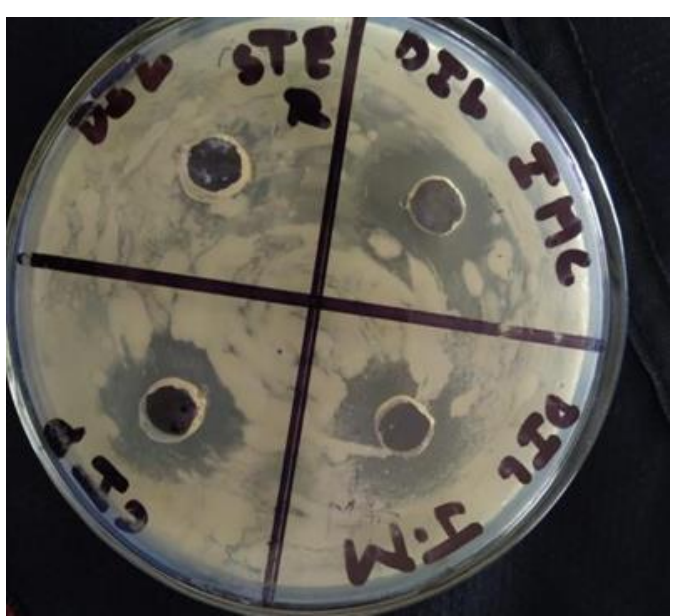

Figure 4: (Plate 2) Antimicrobial study of different hand sanitizers.

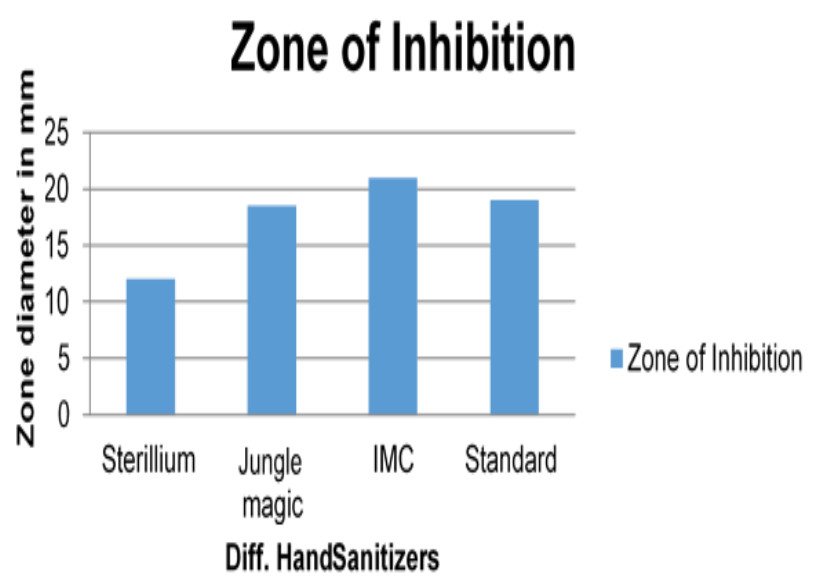

Figure 5: Anti-microbial activity of Sterillium, Jungle magic and IMC dilutions.

\section{SUMMARY AND CONCLUSION}

The present investigation evaluated the antibacterial efficacy of popular brands of hand sanitizers sold in Market. The products showed varying levelof inhibition against the test organisms. S. aureus was the most susceptible to all the products.

The ayurvedic preparation IMC herbal hand sanitizer was found to have greater anti-microbial activity as compared to other hand sanitizers. The sample IMC herbal sanitizer showed maximum zone of inhibition of $21 \mathrm{~mm}$.

In this experimental work, the antibacterial efficacy of popular brands of hand sanitizers sold in market was evaluated. The products showed varying level of inhibition against the test organisms. S. aureus was the most susceptible to all the products. The ayurvedic preparation IMC herbal hand sanitizer was found to have greater anti-microbial activity as compared to other hand sanitizers. 


\section{REFERENCES}

1. Encyclopaedia Britannica http://www.britannica.com/EBchecked/ topic/279225/Hygieia. Accessed: 2014 Mar 05.

2. Semmelweis IP, Die A "tiologie, der Begriff und die Prophylaxis des Kindbettfiebers. Wien, Leipzig: Pest, 1861.

3. Aiello AE, Coulborn RM, Perez V, Larson EL, Effect of hand hygiene on infectious disease risk in the community setting: a meta- analysis. Am J Public Health, 2008; 98: 1372-1382.

4. Hilburn J, Hammond BS, Fendler EJ, Groziak PA, Use of alcohol hand sanitizer as an infection control strategy in an acute care facility. Am J Infect Control, 2003; 31:109116.

5. Curtis V, Cairncross S, Effect of washing hands with soap on diarrhea risk in the community: a systematic review. Infect Dis, 2003; 3: 275-81.

6. WHO, World Health Report 2000. Geneva: World Health Organization: 164.

7. Lindberg E, Adlerberth I, Hesselmar B, Saalman R, Strannegared $A$ et al. High rate of transfer of Staphylococcus aureus from parental skin to infect gut flora. J Clin Microbiol, 2004; 42: 530-534.

8. Jackson Focus: Antimicrobial resistance: Topical antiseptics in health care clinical laboratory science. J Amer Soc Med Tech, 2015;18:160-169.

9. Aiello $A E$, Larson $E$, What is the evidence for causal link between hygiene and infection. Lancet infect Dis, 2002; 2: 103-110.

10. Ray SK, Amarchand R, Srikanth J, Manjum D, A study on prevalence of bacteria on the hands of children and their perception on hand washing in two schools in Bangalore and Kolkata. Ind J public health, 2012;55:293-
297.

11. Watutantrige R, Premalatha P, Lum W, Evelyn C, A study on hand contamination and hand washing practices among medical students. ISRN public Health, 2012; 1-5.

12. Hedderwick S, Mcneil S, Lyons M, Kauffman C, Pathogenic organisms associated with artificial finger nails worn by health care workers. Infection control Hosp Epidemiol, 2000; 21: 505-509.

13. Jain VM, Karibasappa GN, Dodamani AS, Prashanth VK, Mali GV, Comparative assessment of antimicrobial efficacy of different hand sanitizers: An in vitro study; Dental Research Journal | Published by Wolters Kluwer Med know, 2016; 13 (5):424-431

14. Jumaa PA, Hand hygiene: simple and complex. International Journal of Infectious Diseases, 2015; 9(1): 314.

15. Boyce JM, Pittet D Guideline for hand hygiene in health-care settings: recommendations of the Healthcare Infection Control Practices Advisory Committee and the HICPAC/SHEA/APIC/IDSA Hand Hygiene Task Force. Infection Control and Hospital Epidemiology, 2002; 23(S12):S3-S40.

16. Odebisi-Omokanye MB, Ahmed EM, Arshad SO, Oke MA, Comparative Assessment of Antibacterial Efficacy of four popular hand sanitizers sold in Nigeria; Fountain Journal of Natural and Applied Sciences, 2015; 4(1): 01 09.

17. Bauer AW, Kirby WM, Sherris JC, Turck M. Antibiotic susceptibility testing by a standardized single disk method. Am J Clin Pathol, 1966; 45: 4936.

18. Valgas C, De Souza SM, Smania EF, Smania A. Screening methods to determine antibacterial activity of natural products. Braz J Microbio,I 2007; 38: 36980.

Source of Support: The author(s) received no financial support for the research, authorship, and/or publication of this article.

Conflict of Interest: The author(s) declared no potential conflicts of interest with respect to the research, authorship, and/or publication of this article.

For any question relates to this article, please reach us at: editor@globalresearchonline.net New manuscripts for publication can be submitted at: submit@globalresearchonline.net and submit_ijpsrr@rediffmail.com 